\title{
The Utility of Sulfonic Acid Catalysts for Silane Water-Crosslinked Network Formation in the Ethylene-Propylene Copolymer System
}

Kenta ADACHI ${ }^{* \dagger}$, Tomoyuki HIRANO.

* To whom correspondence should be addressed. E-mail: k-adachi@yamaguchi-u.ac.jp

Frontier Research \& Development Department, Matsumura Oil Research Corporation (MORESCO), Kobe, Hyogo, 650-0047, Japan.

$\dagger$ Present address: Department of Environmental Science \& Engineering, Graduate School of Science \& Engineering, Yamaguchi University, Yamaguchi, 753-8512, Japan.

Tel \& Fax: +81-83-933-5731.

Key words: $\quad$ Alkoxysilane, Polyolefin, Kinetics, Sulfonic acid, Hydrolysis, Condensation. 


\begin{abstract}
Catalytic effects of Brönsted acid on the early kinetics of water-crosslinking reaction in the vinyltrimethoxysilane-grafted ethylene-propylene copolymer (EPR-g-VTMS) system were investigated by means of an attenuated total reflectance-Fourier transform infrared (ATR-FTIR) technique and gel fraction measurements. Four sulfonic acids with different substituent, including methanesulfonic acid $\left(\mathrm{C}_{\mathrm{SO}} \mathrm{S}\right), 1$ propanesulfonic acid $\left(\mathrm{C}_{3} \mathrm{SO}_{3} \mathrm{H}\right)$, 1-pentanesulfonic acid $\left(\mathrm{C}_{5} \mathrm{SO}_{3} \mathrm{H}\right)$, and dodecylbenzenesulfonic acid $\left(\mathrm{C} 12 \mathrm{PhSO}_{3} \mathrm{H}\right)$, were selected to examine the progress and effect of progressive changes in the silane watercrosslinked network structure in comparison with a primary amine ( $n$-octadecylamine, Lewis base). From the kinetic analysis using Arrhenius equation, we found that the frequency factors for both hydrolysis (ATRFTIR) and condensation step (gel content) of EPR-g-VTMS decreased in the order of $\mathrm{C}_{1} \mathrm{SO}_{3} \mathrm{H}>\mathrm{C}_{3} \mathrm{SO}_{3} \mathrm{H}>$ $\mathrm{C} 5 \mathrm{SO}_{3} \mathrm{H}>\mathrm{C} 12 \mathrm{PhSO}_{3} \mathrm{H}$, while the activation energy values for each reaction did not differ significantly. These relationships can be explained mainly on the basis of the diffusion factors of the sulfonic acids in EPR$g$-VTMS system. Moreover, the stress-strain curve comparison between water-crosslinked EPR-g-VTMS samples containing sulfonic acid and amine compound clearly indicated the difference in their tensile properties as a result of the catalyst variation; the use of sulfonic acid as water-crosslinking catalyst eventually achieves to the soft and tough water-crosslinked EPR-g-VTMS, while the hard and strong one was produced using amine catalyst. Not only the catalytic activity but also the type of the catalyst has eventually significant effects upon the physical properties of the water-crosslinked EPR-g-VTMS.
\end{abstract}




\section{INTRODUCTION}

Poly- $\alpha$-olefins (POs), such as polyethylene (PE), polypropylene (PP), and their copolymer, can be extruded into various types of products: cables, pipes, sheets, films, adhesive, and so on. [1-3] All these applications are important, but the fact that POs are a thermoplastic with low melt viscosity limits its service temperature to a lower level. There is a need to modify POs in such a way that its thermal stability is increased to endure high service temperatures. For this purpose, POs are crosslinked; that is, their chains are bound together to form a network structure. Crosslinked POs have unique properties that non-crosslinked POs do not. Presently, there are three commercial methods used for the crosslinking of POs: (i) peroxide crosslinking [4], (ii) radiation crosslinking [5], and (iii) silane water-crosslinking [6]. Each method has its own applications according to its particular advantages. The last crosslinking technology is based on the chemistry of organic silicon compounds. [7,8] Unsaturated hydrolysable alkoxysilanes such as vinyltrimethoxysilane (VTMS) are grafted onto POs by using a free-radical reaction. The pendant alkoxysilane groups $(-\mathrm{Si}-\mathrm{OR})$ of resulting polymer hydrolyze in contact with water and yield silanols $(-\mathrm{Si}-\mathrm{OH})$. The three-dimensional crosslinking of the polymer chains is produced by siloxane bonds (-Si-O-Si-) when silanol groups undergo the condensation reaction. [9]

However, this crosslinking reaction is slow in the absence of catalyst. $[10,11]$ To achieve a crosslinking rate of practical importance, the addition of a suitable catalyst is necessary. Among those potential catalysts adopted in commercial products, the organotin compounds (OTCs), such as di- $n$-butyl tin(II) dilaurate (DBTL), are most used for the alkoxysilane water-crosslinking reactions in the PO system. [12-14] However, OTCs are toxics; it has been shown to be potentially carcinogenic. [15-17] Hence, safer catalysts by more environmental friendly are eagerly desired.

We recently investigated the metal acetylacetonate complexes [18] and amine compounds [19] as the catalyst for the water-crosslinking reaction of vinyltrimethoxysilane-grafted ethylene-propylene copolymer (EPR-g-VTMS). The former complexes act Lewis acids and the latter compounds are Lewis bases. 
Presently, we investigated the catalytic effect of Brönsted acid. Four sulfonic acids with different substituent (methanesulfonic acid $\left(\mathrm{C} 1 S O_{3} \mathrm{H}\right), 1$-propanesulfonic acid $\left[\mathrm{C}_{3} \mathrm{SO}_{3} \mathrm{H}\right], 1$-pentanesulfonic acid $\left[\mathrm{C}_{5} \mathrm{SO}_{3} \mathrm{H}\right]$, and dodecylbenzenesulfonic acid $\left[\mathrm{C} 12 \mathrm{PhSO}_{3} \mathrm{H}\right]$ ) were evaluated in the same EPR-g-VTMS system. Results of these studies are reported below. Attenuated total reflectance-Fourier transform infrared (ATR-FTIR) and tensile measurements indicated that the type of catalysis had a substantial influence on the nature of silane water-crosslinked networks and eventually the physical properties. Moreover, we measured the diffusion coefficient of the sulfonic acid in the EPR system. Interestingly, the diffusion coefficients thus determined correlated well with the catalytic activities. The kinetics study revealed that, the smaller the substituent sizes of sulfonic acids, the larger the frequency factors. However, little variation was found for the activation energies of both hydrolysis and condensation reaction in the EPR- $g$-VTMS system. The present finding subjected a route of developing new catalysts for generating water-crosslinked polymer with different physical properties. 


\section{EXPERIMENTAL}

\subsection{Materials.}

The ethylene-propylene copolymer (EPR) with $M_{\mathrm{w}}=2.77 \times 10^{4} \mathrm{~g} / \mathrm{mol}, M_{\mathrm{w}} / M_{\mathrm{n}}=2.3\left(M_{\mathrm{w}}\right.$ : weightaverage molecular weight, $M_{\mathrm{n}}$ : number-average molecular weight), crystallinity $=34.9 \mathrm{wt} \%$, and ethylene/propylene molar ratio $=10.1 / 89.9$ was kindly supplied by Clariant Japan K.K. (Tokyo, Japan). Vinyltrimethoxysilane (VTMS) and dicumyl peroxide (DCP) were purchased from Dow Coring Toray (Tokyo, Japan) and NOF (Tokyo, Japan), respectively. Acetone ( $98 \%)$, chloroform ( 99.5\%), and xylene ( $95 \%)$ were received from Nacalai Tesque Inc., (Kyoto, Japan). Four hydrated sulfonic acids (methanesulfonic acid $\left[\mathrm{C}^{-S_{3}} \mathrm{H}_{3} \mathrm{H}\right]$, 1-propanesulfonic acid $\left[\mathrm{C} 3 \mathrm{SO}_{3} \mathrm{H}\right], 1$-pentanesulfonic acid $\left[\mathrm{C}_{5} \mathrm{SO}_{3} \mathrm{H}\right]$, and dodecylbenzenesulfonic acid $\left[\mathrm{C} 12 \mathrm{PhSO}_{3} \mathrm{H}\right]$ ) were specially supplied by Tokyo Kasei Kogyo Co. Ltd. (Tokyo, Japan) and Shanghai Chemhere Co., Ltd. (Shanghai, China). All materials were used as received without further purification.

\subsection{Determination of Sulfonic Acid Diffusion Coefficient from ATR-FTIR Spectroscopy.}

According to van Alsten's procedure [20], the EPR thin films were prepared by casting the chloroform solution on a ZnSe attenuated total reflectance (ATR) crystal boat cell $(0.5 \mathrm{~cm} \times 4.0 \mathrm{~cm}$, SpectraTech. Inc., USA) in three layers (each sample addition was of $500 \mu \mathrm{l}$ ) and the solvent was allowed to evaporate. The samples were conditioned in a constant humidity chamber $\left(25^{\circ} \mathrm{C}, 60 \% \mathrm{RH}\right)$ for 6 hours prior to the measurement. The thickness of the EPR thin film was measured using a micrometer screw $(5-50 \mu \mathrm{m}$ depending upon the sulfonic acids). The time dependence of the evolution of the characteristic IR absorption bands during penetration of the sulfonic acid through the polymer film deposited on the ATR crystal is measured. Due to the one-dimensional transport characteristics of the system, the sulfonic acid transport into EPR samples can be expressed by the classical Fick's diffusion equation for planar geometries. [21] 


$$
\frac{\partial C_{\text {sulf }}}{\partial t}=D_{\text {sulf }} \frac{\partial^{2} C_{\text {sulf }}}{\partial x^{2}}
$$

Herein, $C_{\text {sulf }}$ is the concentration of the sulfonic acid, $t$ is time, $D_{\text {sulf }}$ is the diffusion coefficient for sulfonic acid molecules, and $x$ is the position. For the assumption of constant boundaries, the solution to Eq.(1) can be written as the following, [22]

$$
\frac{A_{\mathrm{t}}}{A_{\infty}}=1-\frac{8}{\pi \lambda} \sum_{n=0}^{\infty} \frac{(-1)^{n}}{2 n+1} \cdot \frac{1}{\frac{2}{\lambda}+\frac{(2 n+1)^{2} \pi^{2} \lambda}{8 L^{2}}} \cdot \exp \left\{\frac{-D_{\text {sulf }}(2 n+1)^{2} \pi^{2} t}{4 L^{2}}\right\} \ldots \ldots \ldots \ldots \cdots \cdots
$$

where $A_{\mathrm{t}}$ is the absorbance at time $t, A_{\infty}$ is the equilibrium absorbance after total sulfonic acid penetration, $n$ is the number of measurements, $L$ is the thickness of the EPR film, and $\lambda$ is the penetration depth (typically 3-5 $\mu \mathrm{m})$. For the measurement, $1000 \mu \mathrm{l}$ sulfonic acid was spread uniformly on the surface of the sample and, simultaneously, the IR spectrum recording was started. The IR spectra were recorded using a MAGNA-IR 560 FT-IR spectrometer (Nicolet, USA) in a room thermostated at $25 \pm 2{ }^{\circ} \mathrm{C}$.

\subsection{Preparation of Water-Crosslinked EPR-g-VTMS.}

The vinyltrimethoxysilane-grafted ethylene-propylene copolymer (EPR-g-VTMS) was prepared in the molten state by the use of DCP as an initiator. The details of synthesis were described earlier. [23] For the investigation of the catalytic effect, EPR-g-VTMS and sulfonic acid of choice in the amount of $5.0 \times 10^{-4}$ mol/100g EPR resin were mixed in a laboratory open-kneader SV0.5-0.5 (Moriyama, Japan) equipped with two blades co-rotating at ca. $50 \mathrm{rpm}$ at around $120^{\circ} \mathrm{C}$. In a preliminary experiment, no IR spectral change was observed at this juncture, indicating that the water of the hydration of the sulfonic acid has negligible effect on this silane water-crosslinking reaction. EPR-g-VTMS containing sulfonic acid was shaped into $1.4 \mathrm{~mm}$ thick compression-moulded sheets by air pressing. The sheets were cut into pieces of equal size and placed in water maintained at 30,50 , or $80^{\circ} \mathrm{C}$. The samples were then removed from the water bath at the various times 
for examinations of the reaction in progress. To avoid undesired water-crosslinking while waiting for analysis or further treatment, the samples were kept under dried conditions.

\subsection{Hydrolysis and Condensation Analysis of Water-Crosslinked EPR-g-VTMS.}

The ATR-FTIR technique was also used to analyze the degree of the hydrolysis reaction in EPR$g$-VTMS samples. Before the ATR-FTIR measurements, the water-crosslinked EPR-g-VTMS sample sheets were washed with an excess volume of acetone to remove unreacted silane coupling agent or residual peroxide. The IR spectra were recorded using a MAGNA-IR 560 FT-IR spectrometer (Nicolet, USA) equipped with a single reflection Ge attenuated total reflectance accessory (Thunder-dome, Spectra-Tech. Inc., USA) in the range of $600-4000 \mathrm{~cm}^{-1}$ with a resolution of $4 \mathrm{~cm}^{-1}$. The average of 32 spectra was used to increase the signal to noise ratio. The peak intensity of the EPR backbone methylene group at $1460 \mathrm{~cm}^{-1}$ $[24,25]$ was used as an internal reference. In the analysis of the experimental results, the relative absorption peak intensity of the $\mathrm{Si}-\mathrm{OCH}_{3}$ groups stretching of EPR-g-VTMS at $1095 \mathrm{~cm}^{-1}[24,25]$ to that of the $-\mathrm{CH}_{2}-$ groups at $1460 \mathrm{~cm}^{-1}\left(A_{1095} / A_{1460}\right)$ was evaluated.

According to the literature procedure [26,27], the gel content measurements were carried out to evaluate the overall water-crosslinking reaction in EPR-g-VTMS system. Water-crosslinked EPR-g-VTMS samples in a glass wool filter were put into boiling xylene for 12 hours in a Soxhlet extractor apparatus. The extracted samples were washed using acetone, and then dried to a constant weight in a vacuum oven. The gel content is expressed in terms of the percentage of the weight remaining. The gel content is defined as follows:

$$
\text { gel content } / \%=\frac{M_{\mathrm{d}}}{M_{\mathrm{i}}} \times 100
$$

where $M_{\mathrm{i}}$ and $M_{\mathrm{d}}$ are weights of the initial and final dried polymer, respectively. The values of gel fraction deviated from the average by less than $\pm 2 \%$. It is noted that prolonged extraction produced no change in the 
gel content measurements for select samples, and EPR-g-VTMS samples that had not been water-crosslinked contained no gel. The swelling ratio, $q$, is calculated by using the relation:

$$
q=1+\frac{\rho_{\mathrm{p}} M_{\mathrm{s}}}{\rho_{\mathrm{s}} M_{\mathrm{d}}}
$$

where $\rho_{\mathrm{p}}$ and $\rho_{\mathrm{s}}$ are the polymer and the solvent density, respectively, and $M_{\mathrm{s}}$ is the weight of the polymer swelled with solvent. According to the theory of Flory and Rehner, [28] the average molecular weight between crosslinks, $M_{\mathrm{c}}$, is defined as follows:

$$
M_{\mathrm{c}}=-V \rho_{\mathrm{p}} \frac{\left(\sqrt[3]{\phi_{\mathrm{p}}}-\frac{\phi_{\mathrm{p}}}{2}\right)}{\left[\ln \left(1-\phi_{\mathrm{p}}\right)+\phi_{\mathrm{p}}+\chi \phi_{\mathrm{p}}^{2}\right]},
$$

where $V$ is the molar volume of the solvent, $\rho_{\mathrm{p}}$ is the polymer density, $\phi_{\mathrm{p}}$ is the volume fraction of polymer in the swollen gel, and $\chi$ is the Flory-Huggins interaction parameter between solvent and polymer. The molar valume of xylene molecule is $122 \mathrm{~cm}^{3} / \mathrm{mol}$. The $M_{\mathrm{c}}$ value is one of the most important structural parameters characterising a crosslinked polymer, which is directly related to the crosslink density. $\phi_{\mathrm{p}}$ value is calculated using the swelling ratio, $q$ :

$$
\phi_{\mathrm{p}}=\frac{1}{q}
$$

The Flory-Huggins interaction parameter between solvent and polymer, $\chi$, is given by:

$$
\chi=V \frac{\left(\delta_{\mathrm{s}}-\delta_{\mathrm{p}}\right)^{2}}{R T}
$$

where $\delta_{\mathrm{s}}$ and $\delta_{\mathrm{p}}$ are the cohesive energy density of solvent and polymer, respectively, $R$ indicates the universal gas constant. $T$ is the absolute temperature $(K)$. The $\delta_{\mathrm{s}}$ and $\delta_{\mathrm{p}}$ values used in this study are 18.3 $\mathrm{MPa}^{0.5}$ and $15.2 \mathrm{MPa}^{0.5}$, respectively. [29] 


\subsection{Tensile Measurement of Water-Crosslinked EPR-g-VTMS}

Tensile properties of the water-crosslinked samples (aged in $80^{\circ} \mathrm{C}$ water for 24 hours) containing various sulfonic acids were performed with a tensile tester AUTOGRAPH AGS-H 500N (Shimadzu Co. Ltd., Japan). The measurements were carried out by using tensile speed of $100 \mathrm{~mm} / \mathrm{min}$ in a room thermostated at $25 \pm 2{ }^{\circ} \mathrm{C}$. The dumbbell specimens (no. 6 of Japan Industrial Standard, JIS K 6251) were subjected to the measurement. 


\section{RESULTS AND DISCUSSION}

\subsection{Diffusion Behavior of Various Sulfonic Acids in EPR System.}

Since the silane water-crosslinking kinetics should depend upon the catalysts' diffusion behavior, it is interesting and important to study the diffusion coefficients in a polymer containing various catalytic compounds. We investigated the diffusion behavior of various sulfonic acids in the ethylene-propylene copolymer (EPR) using the ATR-FTIR technique. After the initial FTIR spectra were obtained, the ATR boat cell, which bottom surface was cast by the EPR thin-film, was filled with the sulfonic acid, IR spectra were taken at regular intervals, and the changes in the spectra were examined. A typical pattern of the time dependence of the ATR-FTIR spectra during penetration of $\mathrm{C}_{1} \mathrm{SO}_{3} \mathrm{H}$ into the EPR film is shown in Fig. 1(a). The increase in the $\mathrm{C} 1 \mathrm{SO}_{3} \mathrm{H}$ bands, containing the asymmetric and symmetric $\mathrm{SO}_{2}$ stretching vibration (1325 and $1121 \mathrm{~cm}^{-1}$, respectively), the $-\mathrm{CH}_{3}$ rocking vibration $\left(985 \mathrm{~cm}^{-1}\right)$, and the $\mathrm{C}-\mathrm{S}$ stretching vibration band

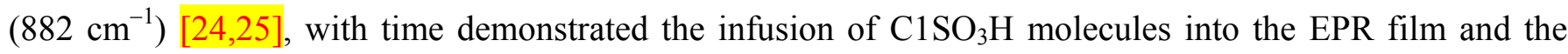
increase of $\mathrm{C}_{1} \mathrm{SO}_{3} \mathrm{H}$ concentration. Although minor differences did exist, similar spectral changes were observed in other sulfonic acids. For the calculation of the diffusion coefficient $\left(D_{\text {sulf }}\right)$, the intensity of the absorption band at around $1120 \mathrm{~cm}^{-1}$ (the symmetric $\mathrm{SO}_{2}$ stretching vibration mode) was used. This absorption peak intensity was not affected by background signal (the intensity of the background region was less than $1 \%$ of the total band). The increase in the relative peak intensity $\left(A_{t} / A_{\infty}\right)$ is shown in Fig. $1(\mathrm{~b})$ as a typical result. In all of the experiments, an initially rapid increase in absorbance intensity of the sulfonic acid band was seen, followed by a gradual increase to an asymptotic value. This plateau region is attributed to the diffusion equilibrium. Analysis of the absorbance data using the Fick's equation (Eq.(2)) will yield the apparent diffusion constant for sulfonic acids $\left(D_{\text {sulf }}\right)$ through EPR thin layer for each experiments. As shown in Fig. 1(b), reasonable agreement between the experimental and Fick's equation fitting data was observed. The diffusion coefficients determined by the ATR-FTIR technique are summarized in Table 1 . The obtained 
$D_{\text {sulf }}$ value of the sulfonic acid decreased from $10^{-13}$ to $10^{-16} \mathrm{~m}^{2} \mathrm{~s}^{-1}$ order as the calculated molar volume increased. [30] Importance of the steric hindrance effect is revealed.

\subsection{Accelerated Kinetics of Hydrolysis Reaction by Sulfonic Acid Compounds in EPR-g-VTMS System.}

The reaction sequence for the water-crosslinking reaction in EPR-g-VTMS system is shown in Scheme 1. Three reaction steps are involved: the water diffusion, the hydrolysis, and the condensation. [9] In the hydrolysis step, the methoxysilane groups $\left(-\mathrm{Si}-\mathrm{OCH}_{3}\right)$ grafted to the EPR backbone form silanol groups by the reaction with water molecule, and in the final step, two of these condense and a siloxane bond $(-\mathrm{Si}-\mathrm{O}-\mathrm{Si}-)$ is formed.

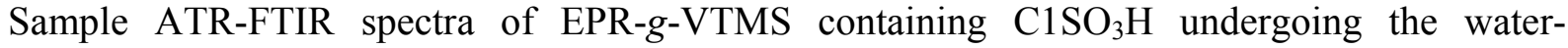
crosslinking reaction are shown in Fig. 2(a). For the cases using other sulfonic acid compounds, similar spectral changes were observed (not shown). In Figure 2(a), two novel peaks appear at 890 and $1048 \mathrm{~cm}^{-1}$ and increase in intensity with aging time. Concurrently, the peaks at 1095 and $1193 \mathrm{~cm}^{-1}$, which correspond to $\mathrm{Si}-\mathrm{O}$ stretching and $\mathrm{Si}-\mathrm{C}$ stretching vibration of the methoxysilane groups $\left(\mathrm{C}-\mathrm{Si}-\mathrm{OCH}_{3}\right)$, respectively [24,25,31,32], decrease monotonically. The absorptions at 890 and $1048 \mathrm{~cm}^{-1}$ are due to silanol $(-\mathrm{Si}-\mathrm{OH})$ and single siloxane (-Si-O-Si-; see Scheme 1), respectively. [33] Those results indicate that the degree of the water-crosslinking reaction (hydrolysis and condensation) of EPR-g-VTMS can be directly monitored using ATR-FTIR technique.

A comparison of the ATR-FTIR spectra of the water-crosslinked EPR-g-VTMS in the presence of sulfonic acid $\left(\mathrm{C} 1 \mathrm{SO}_{3} \mathrm{H}\right)$ and primary amine compound (n-octadecylamine) is also shown in Figure 2(a) and (b), respectively. Inspection of this figure immediately revealed that (1) the multi siloxane linkage band $\left(-\mathrm{Si}=(\mathrm{O})_{2}=\mathrm{Si}-\right.$ or $-\mathrm{Si} \equiv(\mathrm{O})_{3}=\mathrm{Si}-;$ see $\mathrm{Scheme} \mathrm{1)}$ at $1120 \mathrm{~cm}^{-1}[33]$ hardly develops in the case of sulfonic acid, and (2) the silanol band ( $\mathrm{Si}-\mathrm{OH})$ at $890 \mathrm{~cm}^{-1}$ develops strongly in the case of the sulfonic acid, but not in the case of amine compound. This difference will be discussed later. 
The extent of the hydrolysis step (in Scheme 1) of methoxysilane groups could be determined from the intensity ratio $\left(A_{1095} / A_{1460}\right)$ of the absorption peak at $1095 \mathrm{~cm}^{-1}\left(\mathrm{Si}-\mathrm{OCH}_{3}\right.$ group) to the reference peak at $1460 \mathrm{~cm}^{-1}\left(-\mathrm{CH}_{2}-\right.$ groups in backbone). Figure 3 shows the observed temporal changes of $A_{1095} / A_{1460}$ ratio from the reaction catalyzed by $\mathrm{C} 1 \mathrm{SO}_{3} \mathrm{H}$ and $\mathrm{C} 12 \mathrm{PhSO}_{3} \mathrm{H}$ and run at four different temperatures. The initial rate, $r_{\text {hyd }}^{0}\left(\right.$ hour $\left.^{-1}\right)$, of hydrolysis reaction given by Eq. (8) may be obtained by differentiating the quadratic equation fitted to the observed points.

$$
r_{\mathrm{hyd}}^{0}=\left|\frac{d\left(A_{1095} / A_{1460}\right)}{d t}\right|_{t=0}
$$

Our previous study revealed that the observed initial hydrolysis rate increased linearly with the increase in the methoxysilane group concentration. [23] We therefore concluded that the hydrolysis step in Scheme 1 was mostly controlled by the hydrolysis rate and little affected by the diffusion rate of water. Figure 4 shows the observed initial hydrolysis rate (in the logarithmic scale) plotted against the reciprocal absolute temperature for all the experiments catalyzed by the four sulfonic acids. As is well-known, the apparent rate constant, $r_{\text {hyd }}^{0}$, is given by the Arrhenius relationship:

$$
r_{\text {hyd }}^{0}=A_{\text {hyd }} \exp \left(\frac{-E_{\text {a,hyd }}}{R T}\right)
$$

where $A_{\text {hyd }}$ is the frequency factor, $T$ is the absolute temperature, $R$ is the gas constant, and $E_{\text {a,hyd }}$ is the activation energy for the hydrolysis step. Thus, the minus slopes of the fitted lines in these plots are corresponding to the activation energies and $y$-intercepts are the frequency factors. Both values for all sulfonic acids are also illustrated in Table 1. It is thus revealed that the activation energies for hydrolysis step are essentially the same for all four sulfonic acid. However, the frequency factors show a large variation. The smaller the molar volume of sulfonic acid is, the larger the frequency factor is, which is probably due to the diffusion behavior of these sulfonic acid compounds in EPR-g-VTMS. 


\subsection{Condensation Kinetics of EPR-g-VTMS Evaluated by Gel Fraction Measurements.}

The quantity of gel is generally used to evaluate the crosslinking degree of resins and rubbers. $[34,35]$ In this study, the gel content measurement is used to study the kinetics of the condensation step of EPR-g-VTMS in the presence of sulfonic acid compounds. Figure 5 shows the temporal changes of gel content in EPR-g-VTMS system containing sulfonic acid observed at three different temperatures. As expected, the rate and degree of overall water-crosslinking increased with aging temperature. As indicated, the initial overall water-crosslinking reaction rate, $r_{\text {crk }}^{0}\left(\%\right.$ hour $\left.^{-1}\right)$, can be obtained from this data as the initial hydrolysis rate obtained from Fig. 3:

$$
r_{\mathrm{crk}}^{0}=\left|\frac{d \text { (gel content })}{d t}\right|_{t=0} .
$$

Figure 6 shows the corresponding of logarithmic initial overall water-crosslinking reaction rates of EPR-gVTMS with various sulfonic acids as a function of the reciprocal absolute temperature. From the Arrhenius equation (see Eq.(11)), the activation energy for the overall water-crosslinking reactions, $E_{\mathrm{a}, \text { crk }}$ and the frequency factor, $A_{\text {crk }}$, can be obtained from the slope and $y$-intercept, respectively.

$$
r_{\text {crk }}^{0}=A_{\text {crk }} \exp \left(\frac{-E_{\mathrm{a}, \mathrm{crk}}}{R T}\right),
$$

The results are including in Table 1 . As with the case of the hydrolysis step, all of the four sulfonic acids showed essentially the same activation energy values, but frequency factors decreased as the molar volume increased. The results indicated that the overall water-crosslinking reaction rate was also influenced by the difference in the diffusion coefficient of the catalyst in the EPR.

In order to determinate the degree of crosslinking achieved, the swelling examinations were performed with xylene. The average molecular weight between crosslinks, $M_{\mathfrak{c}}$, was calculated using the Flory-Rehner equation (see Eq.(5)). The $M_{\mathrm{c}}$ value is the dominating factors in prescribing the behavior of a given type of crosslinked polymer. [36,37] The variation of the $M_{\mathrm{c}}$ values of EPR- $g$-VTMS aged in $80^{\circ} \mathrm{C}$ 
water for 24 hours with various sulfonic acids is also listed in Table 1. There is no noteworthy difference between the $M_{\mathrm{c}}$ values of EPR- $g$-VTMS catalyzed by the various sulfonic acids. The $M_{\mathrm{c}}$ value obtained by primary amine compound is also shown in Table 1 , but considerably smaller than the ones obtained by sulfonic acids. In the previous section where the hydrolysis step was examined by means of ATR-FTIR technique, it was run that, in the sulfonic acid-catalyzed system, the condensation step did not progress to the same extent achieved by primary amine compound (see Fig. 2). Therefore, it is reasonable that there is a significant margin between $M_{\mathrm{c}}$ values of EPR- $g$-VTMS catalyzed by sulfonic acid and amine compound.

Just as with the alkoxysilane hydrolysis-condensation reaction, the relative reaction rate mainly depends upon the steric effects and the charge on the transition state. [38-40] Thus, for acid-catalyzed hydrolysis with a positively charged transition state stabilized by electron-donating group, mono-silanol $\left[-(\mathrm{RO})_{2} \mathrm{SiOH}\right]$ condenses faster than di-silanol $\left[-\mathrm{ROSi}(\mathrm{OH})_{2}\right]$, that is, which condenses much faster than trisilanol $\left[-\mathrm{Si}(\mathrm{OH})_{3}\right]$. On the other hand, in base-catalyzed conditions, the negatively charged transition state becomes more stable as more hydroxyl groups replace the electron-donating alkoxy groups. Therefore, successive hydrolysis steps occur increasingly rapidly, and the fully hydrolyzed species undergoes the fastest water-condensation reaction. In summary, it can generally be said that sol-gel derived siloxane networks, under acid-catalyzed conditions, yield primarily sparsely or weakly branched clusters which entangle and form additional branches resulting in gelation (so-called "cluster-cluster growth" [41]), whereas, under basecatalyzed conditions, they yield more highly branched clusters which do not interpenetrate prior to gelation and thus behave as discrete clusters (so-called "monomer-cluster growth" [41]). [7,8] Inspired by this knowledge, we concluded the following: the use of sulfonic acid catalyst in the EPR-g-VTMS system yields the water-crosslinked network structure, consisting of single siloxane linkages (stage A, see Scheme 1), with much free volume due to unreacted alkoxysilane and/or silanol groups. In contrast, the water-crosslinked EPR-g-VTMS catalyzed by amine compound consists of the high-density network structure due to multiple siloxane linkages (stage B or C). 


\subsection{Tensile Properties of Water-Crosslinked EPR-g-VTMS.}

The stress-strain curve generally uses to characterize the dynamic behavior of crosslinked polymer. Tensile stress-strain curve of water-crosslinked EPR-g-VTMS catalyzed by $\mathrm{C}_{1} \mathrm{SO}_{3} \mathrm{H}$ (aged in $80^{\circ} \mathrm{C}$ water for 24 hours) is shown in Fig. 7. As references, tensile stress-strain curves of uncrosslinked EPR-gVTMS (non catalyst) and water-crosslinked EPR-g-VTMS containing amine compound (n-octadecylamine) are displayed in this figure. It is seen that the water-crosslinking reaction increases tensile properties and that the increase depends upon the catalyst used. Following the stress-strain curve types defined by Carswell and Nason [42], the use of sulfonic acid catalyst achieves the soft and tough type water-crosslinked EPR-gVTMS, while the amine catalyst produces the hard and strong type. It is also seen in Fig. 7 that, at the break point, the amine-catalyzed EPR-g-VTMS shows the higher tensile modulus and the lower elongation (9.5 MPa and $246 \%$, respectively), whereas the sulfonic acid-catalyzed one shows the lower tensile modulus and the higher elongation (7.3 $\mathrm{MPa}$ and $510 \%$, respectively). Incidentally, other $\mathrm{C}_{3} \mathrm{SO}_{3} \mathrm{H}, \mathrm{C}_{5} \mathrm{SO}_{3} \mathrm{H}$, and $\mathrm{C}_{12} \mathrm{PhSO}_{3} \mathrm{H}$ systems showed the stress-strain curves, the breaking strength values, and the percentage

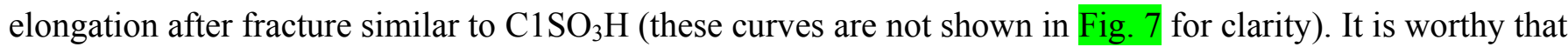
these differences in the tensile modulus and elongation depending on the type of the catalyst can be consistent with the one in $M_{\mathrm{c}}$ values. 


\section{CONCLUSION}

A catalytic effect of four sulfonic acid compounds with different substituent group $\left(\mathrm{C}^{\mathrm{SO}}{ }_{3} \mathrm{H}\right.$, $\mathrm{C} 3 \mathrm{SO}_{3} \mathrm{H}, \mathrm{C}_{5} \mathrm{SO}_{3} \mathrm{H}$, and $\mathrm{C} 12 \mathrm{PhSO}_{3} \mathrm{H}$ ) in the water-crosslinking reaction (hydrolysis and condensation) of alkoxysilane-grafted ethylene-propylene copolymers (EPR- $g$-VTMS) was investigated by means of an attenuated total reflectance-Fourier transform infrared (ATR-FTIR) technique and gel fraction measurements. The kinetic study of alkoxysilane water-crosslinking reaction revealed that all of sulfonic acid compounds chosen in this study have a high catalytic activity. From the analysis using Arrhenius equation, we found that the sulfonic acid compounds with the small substituent had a larger frequency factor for both hydrolysis and condensation reactions than with the large one, whereas the activation energy values for each reaction did not differ significantly. The differences in kinetics would mostly be attributed to the diffusion effects of sulfonic acid compounds due to the different organic substituent; the sulfonic acid with the large substituent diffuses more slowly than the small one in EPR-g-VTMS system. Moreover, the comparison with water-crosslinked EPR-g-VTMS containing the primary amine compound clearly indicated that the type of catalysis (acid or base) has a substantial influence on the nature of siloxane bands and eventually the physical tensile properties. Actually, most of the catalytic trends in this study could be explained by the traditional silicate sol-gel knowledge. $[7,8,41]$

Based on the sol-gel chemistry knowledge and experimental findings in this study, a possible catalytic mechanism of sulfonic acid is shown schematically in Scheme 2. The diffusion behavior of sulfonic acid plays an important role in the silane water-crosslinking kinetics in EPR-g-VTMS system. Moreover, the fact that sulfonic acid is much effective catalyst may be explained by the double catalytic activity for the hydrolysis and condensation reaction in EPR-g-VTMS system. The intermediate with thermodynamically stable six-membered ring $[19,43]$ would be formed through the hydrogen bonding at the penta-coordinating silica in both reactions. However, a detailed interpretation for this catalytic mechanism has not been known yet. Further investigation of the overall silane water-crosslinking reaction in EPR-g-VTMS system using 
various acid compounds such as sulfonic, carboxylic, nitric, and boric acid and their analogous compounds will be the subject of future study. We believe that the results in this study are very important in understanding a comprehensive catalytic mechanism for the water-crosslinking reaction of alkoxysilane groups, and also aid in an investigation of novel crosslinking catalysts for silicon resin chemistry. 


\section{ACKNOWLEDGEMENT}

The author (K.A.) acknowledges Dr. Paul H. Kasai (MORESCO) for their helpful supports and advices and for fruitful discussions. 


\section{References}

[1] Seymour RB, Cheng TC (eds), (1988) Advances in Polyolefins: The World's Most Widely Used Polymers 1st ed., Springer-Verlag, NY, USA.

[2] Vasile C (ed), (2000) Handbook of Polyolefins 2nd ed., CRC press, FL, USA.

[3] Nwabunma D, Kyu T (eds), (2007) Polyolefin Blends, Wiley-Interscience, NJ, USA.

[4] Smedberg A, Hjertberg T, Gustafsson B, (2003) Polymer 44:3395-3405.

[5] Gheysari D, Behjat A, (2001) Eur. Polym. J. 37:2011-2016.

[6] Wang Z, Hu Y, Gui Z, Zong R, (2003) Polymer Testing 22:533-538.

[7] Wright JD, Sommerdijk NAJM, (2000) Sol-Gel Materials: Chemistry and Applications, CRC press, Florida, USA.

[8] Hench LL, West JK, (1990) Chem. Rev. 90:33-72.

[9] Al-Malaika S (ed), (1997) Reactive modifiers for polymers. Blackie Academic and Professional, London, UK.

[10] Plueademann EP, (2003) Silane Coupling Agents, Springer, Heidelberg.

[11] Sultan BA, Palmlöf M, (1994) Plast. Rubber Comp. Process. Appl. 21:65-73.

[12] van der Weij FW, (1980) Makromol. Chem. 181:2541-2548.

[13] Toynbee J, (1994) Polymer 35:438-440.

[14] Shieh Y-T, Chuang H-C, Liu C-M, (2001) J. Appl. Polym. Sci. 81:1799-1807.

[15] Fent K, (1996) Crit. Rev. Toxicol. 26:1-117.

[16] Cledón M, Theobald N, Gerwinski W, Penchaszadeh PE, (2006) J. Mar. Biol. Assoc. UK. 86:751-754.

[17] Doering DD, Steckelbroeck S, Doering T, Klingmüller D, (2002) Steroids 67:859-887.

[18] Adachi K, Hirano T, (2008) Eur. Polym. J. 44:542-549.

[19] Adachi K, Hirano T, (2008) Ind. Eng. Chem. Res. 47:1812-1819.

[20] van Alsten JG, (1995) Trends Polym. Sci. 3:272-276.

[21] Smith WF, (2004) Foundations of Materials Science and Engineering 3rd ed., McGraw-Hill, NY, USA.

[22] Crank J, (1956) The Mathematics of Diffusion, Oxford University Press, Oxford, UK.

[23] Adachi K, Hirano T, Fukuda K, Nakamae K, (2007) Macromol. React. Eng. 1:313-320.

[24] Socrates G, (2001) Infrared and Raman Characteristic Group Frequencies: Tables and Charts (3rd Edition), John Wiley \& Sons, New York, USA.

[25] Silverstein RM, Bassler GC, Morrill TC, (1991) Spectrometric Identification of Organic Compounds (5th Edition), John Wiley \& Sons, New York, USA. 
[26] Sirisinha K, Kawko K, (2005) Macromol. Mater. Eng. 290:128-135.

[27] Sirisinha K, Chimdist S, (2006) Polymer Testing 25:518-526.

[28] Barton AFM, (1983) Handbook of Solubility Parameters and Other Cohesion Parameters, CRC Press, Boca Raton, Florida, USA.

[29] Barton AFM, (1985) Pure \& Appl. Chem. 57:905-912.

[30] ACD-Lab software for calculating the referred physicochemical parameters; www.acdlabs.com.

[31] Brandrup J, Immergut EH (eds), (1989) Polymer Handbook, (3rd Edition), John Wiley \& Sons, New York, USA.

[32] Hjertberg T, Palmlof M, Sultan B-A, (1991) J. Appl. Polym. Sci. 42:1185-1192.

[33] Gazel A, Lemaire J, Laurenson P, Roche G, (1985) Makromol. Chem. Rapid Commun. 6:235-240.

[34] DeGennes PG, (1979) Scaling Concepts in Polymer Physics; Oxford University Press: Oxford, UK.

[35] Harland RS, Peppas NA, (1989) Colloid Polym. Sci. 267:218-225.

[36] Narkis M, Tzur A, Vaxman A, Fritz HG, (1985) Polym. Eng. Sci. 25:857-862.

[37] Shieh Y-T, Liau J-S, Chen T-K, (2001) J. Appl. Polym. Sci. 81:186-196.

[38] Aelion R, Loebel A, Eirich F, (1950) J. Am. Chem. Soc. 72:5705-5712.

[39] Grubb WT, (1954) J. Am. Chem. Soc. 76:3408-3414.

[40] Brinker CJ, (1988) J. Non-Cryst. Solids 100:31-50.

[41] Brinker CJ, Scherer GW (eds), (1990) Sol-Gel Science: The Physics and Chemistry of Sol-Gel Processing, Academic Press, NY, USA.

[42] Carswell TS, Nason HK, (1944) Modern Plastics, 21:121-126.

[43] Okumoto S, Fujita, N, Yamabe S, (1998) J. Phys. Chem. A, 102:3991-3998. 


\section{Figure Captions}

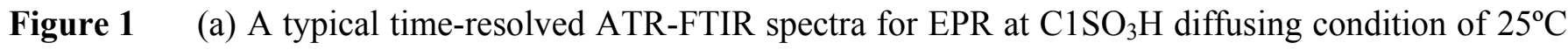
(upper) and spectrum of free $\mathrm{C}_{1} \mathrm{SO}_{3} \mathrm{H}$ (bottom), (b) Time dependence of the change in ATR-FTIR absorption intensity (at $1121 \mathrm{~cm}^{-1}$ of the $\mathrm{SO}_{2}$ symmetric stretching vibration band) during penetration of $\mathrm{C}_{1} \mathrm{SO}_{3} \mathrm{H}$ into the thin EPR film at $25^{\circ} \mathrm{C}$. Solid lines were obtained from the analysis with Eq. (2).

Figure 2 The spectral change due to the water-crosslink reaction of EPR-g-VTMS in the presence of (a) $\mathrm{C}_{1 \mathrm{SO}_{3} \mathrm{H}}\left(5.0 \times 10^{-4} \mathrm{~mol} / 100 \mathrm{~g}\right.$ EPR resin) and (b) primary amine ( $n$-octadecylamine, $5.0 \times 10^{-4} \mathrm{~mol} / 100 \mathrm{~g}$ EPR resin) measured by ATR-FTIR technique. For peak assignment, see text.

Figure 3 Time profile of $A_{1095} / A_{1460}$ ratio of water-crosslinked EPR- $g$-VTMS in the presence of (a) $\mathrm{C} 1 \mathrm{SO}_{3} \mathrm{H}$ and (b) $\mathrm{C} 12 \mathrm{PhSO}_{3} \mathrm{H}$ at $30^{\circ} \mathrm{C}(\square), 50^{\circ} \mathrm{C}(\triangle)$, and $80^{\circ} \mathrm{C}(\bigcirc)$.

Figure 4 Plots of logarithmic hydrolysis rates as a function of reciprocal absolute temperature for EPR-gVTMS in the presence of various sulfonic acids. Solid lines were obtained from the analysis with Eq. (9).

Figure 5 Time profile of gel content of water-crosslinked EPR- $g$-VTMS in the presence of (a) $\mathrm{C}_{1} \mathrm{SO}_{3} \mathrm{H}$ and (b) $\mathrm{C} 12 \mathrm{PhSO}_{3} \mathrm{H}$ at $30^{\circ} \mathrm{C}(\square), 50^{\circ} \mathrm{C}(\triangle)$, and $80^{\circ} \mathrm{C}(\bigcirc)$.

Figure 6 Plots of logarithmic overall water-crosslinking rates as a function of reciprocal absolute temperature for EPR-g-VTMS in the presence of various sulfonic acids. Solid lines were obtained from the analysis with Eq. (11).

Figure 7 Effect of catalyst upon the stress-strain curves of water-crosslinked EPR-g-VTMS (O: aminecatalyzed EPR-g-VTMS, $\triangle$ : sulfonic acid-catalyzed EPR-g-VTMS, $\square$ : uncrosslinked EPR-g-VTMS). 


\section{$\underline{\text { Scheme titles }}$}

Scheme 1 Water-crosslinking (water-diffusion, hydrolysis, and condensation) reaction pathway in silanegrafted polyolefin system.

Scheme 2 Possible catalytic cycle for sulfonic acid-catalyzed alkoxysilane hydrolysis and condensation reaction in silane-grafted polyolefin system. 
Figure 1
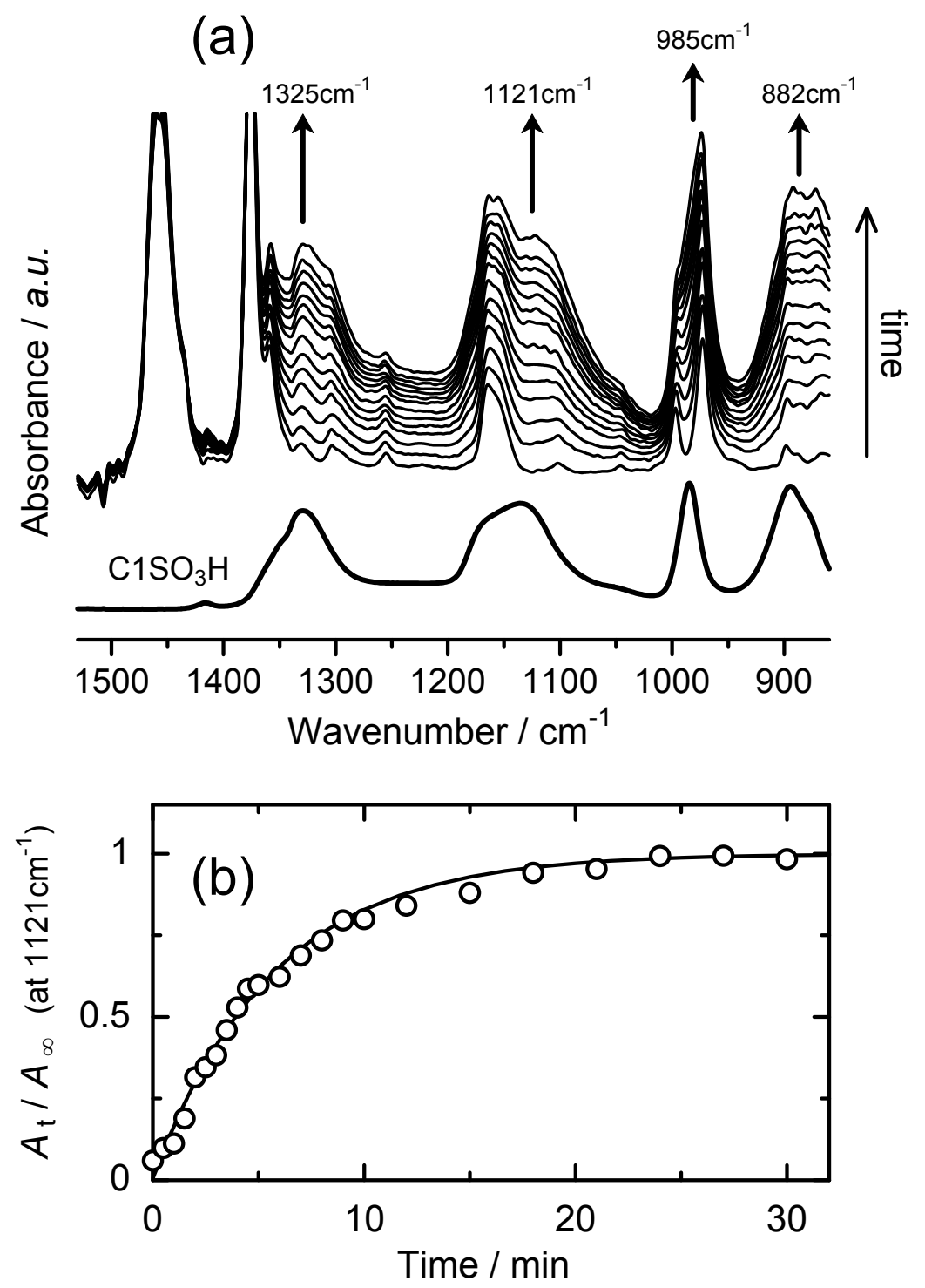
Figure 2
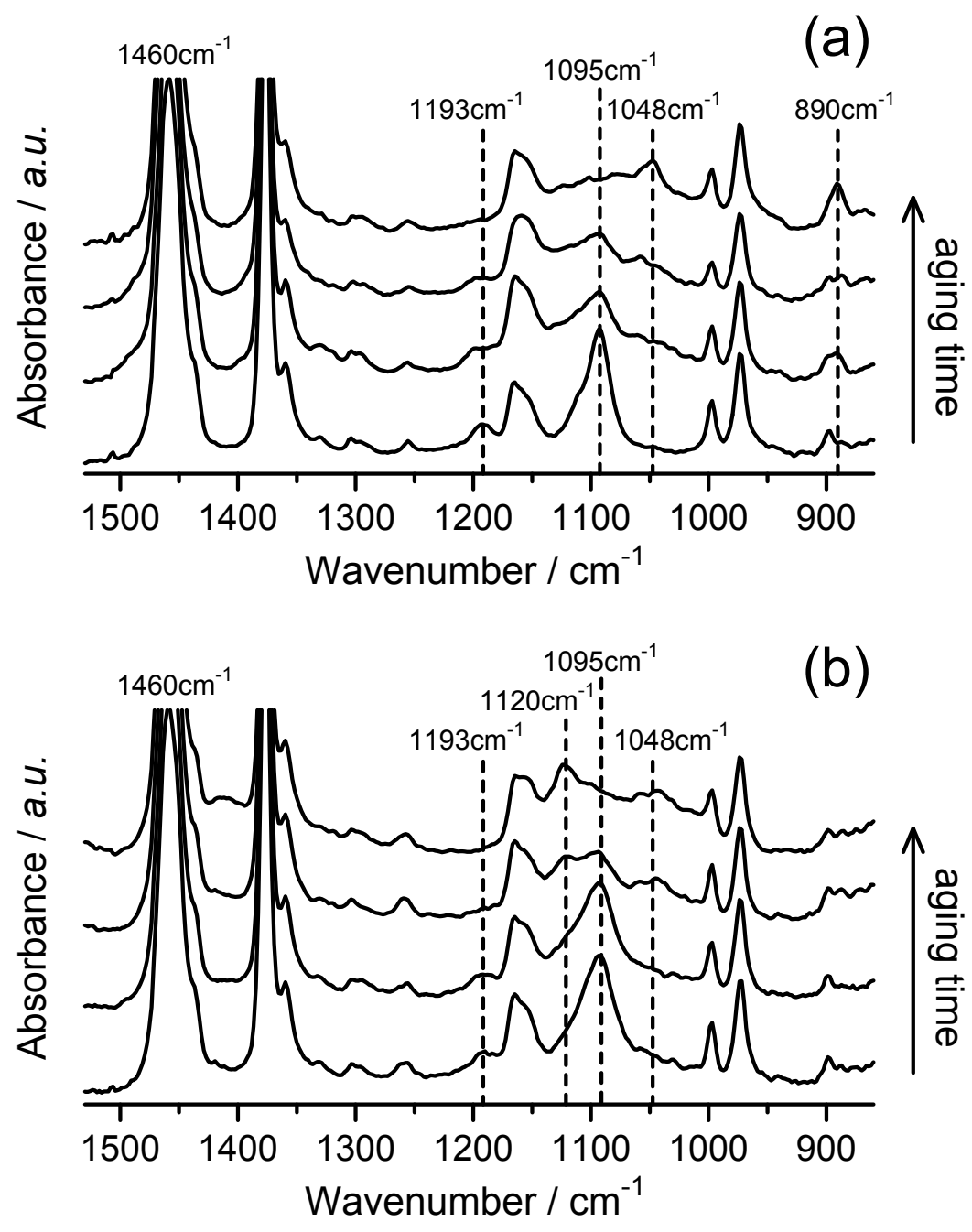
Figure 3

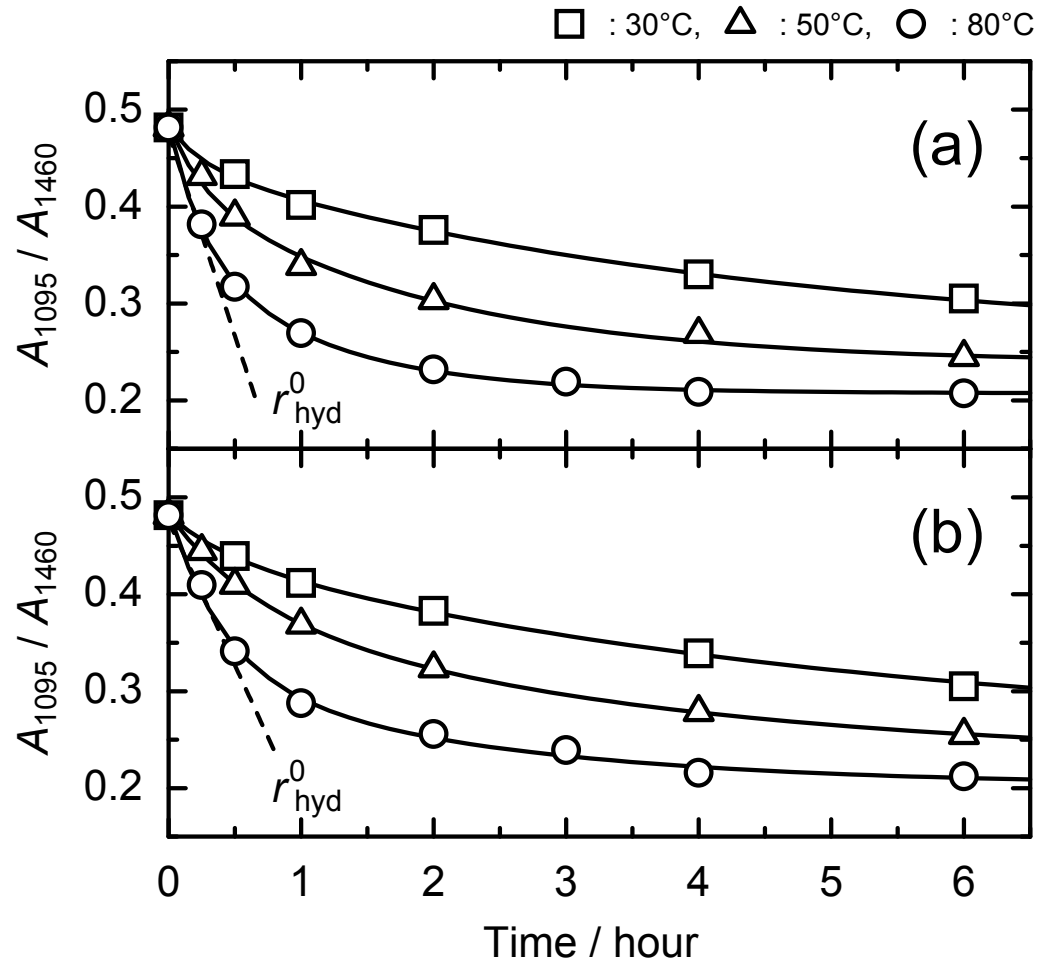


Figure 4

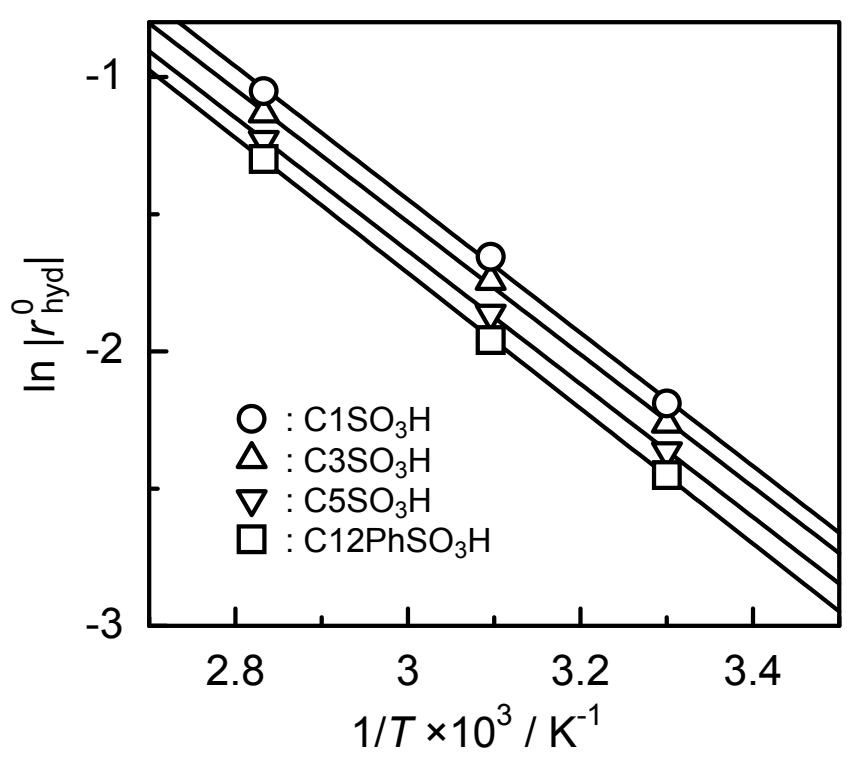


Figure 5

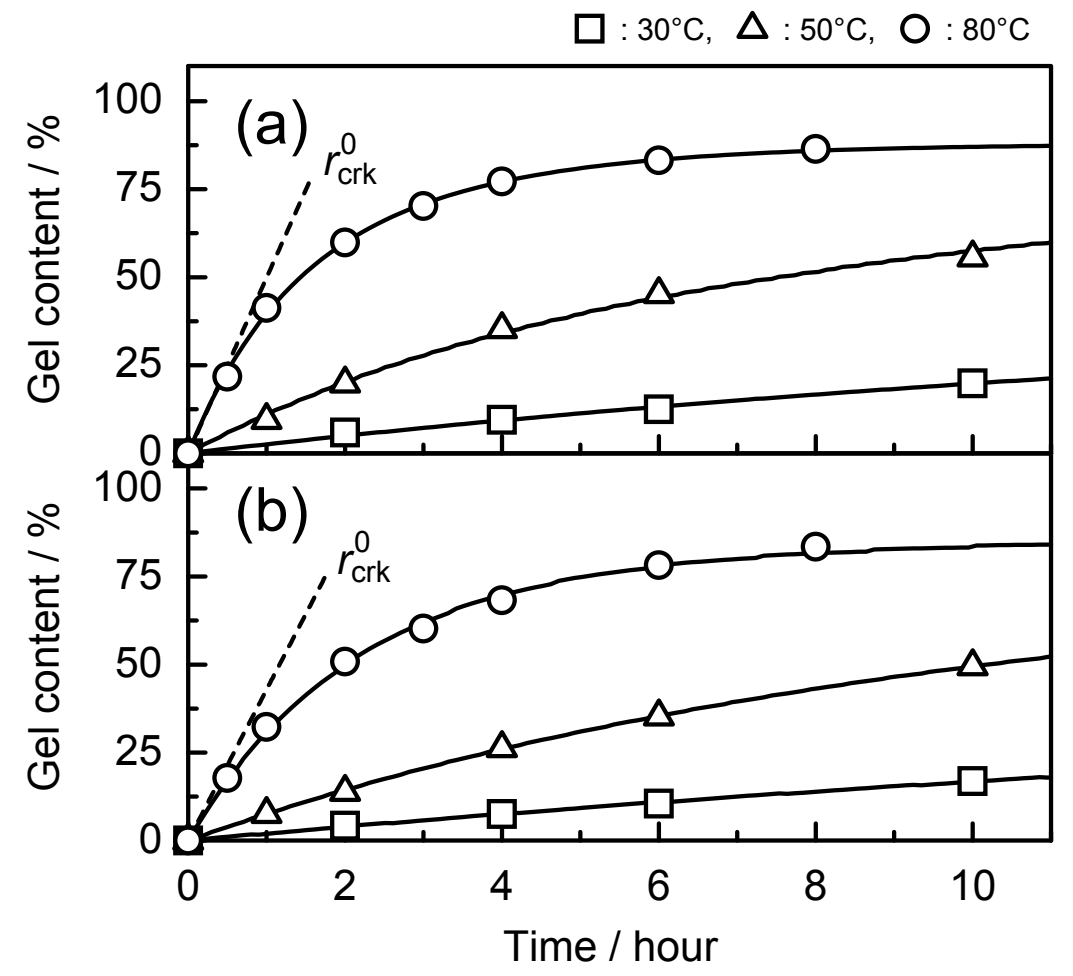


Figure 6

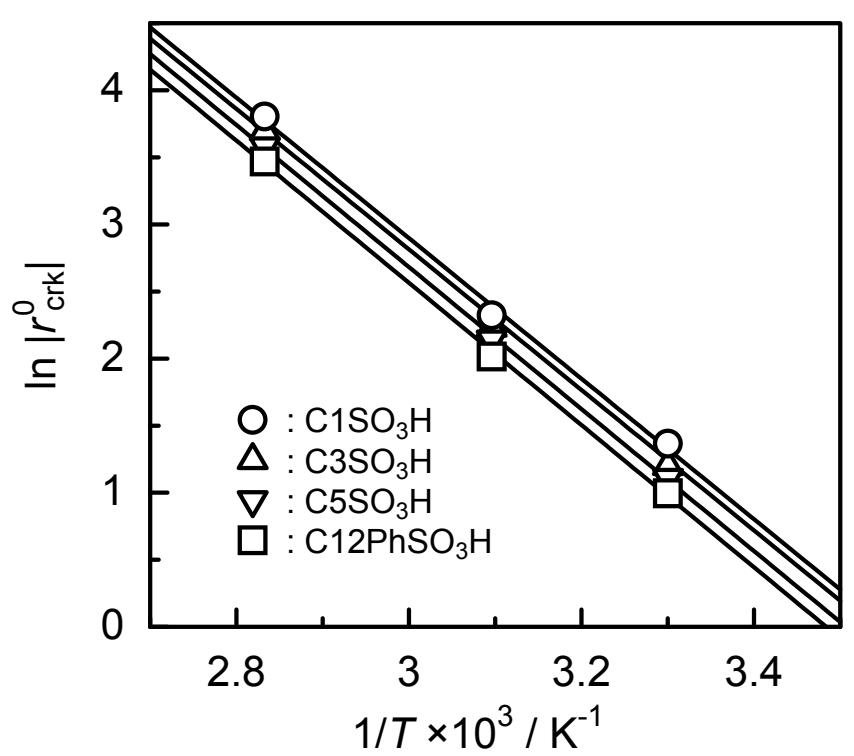


Figure 7

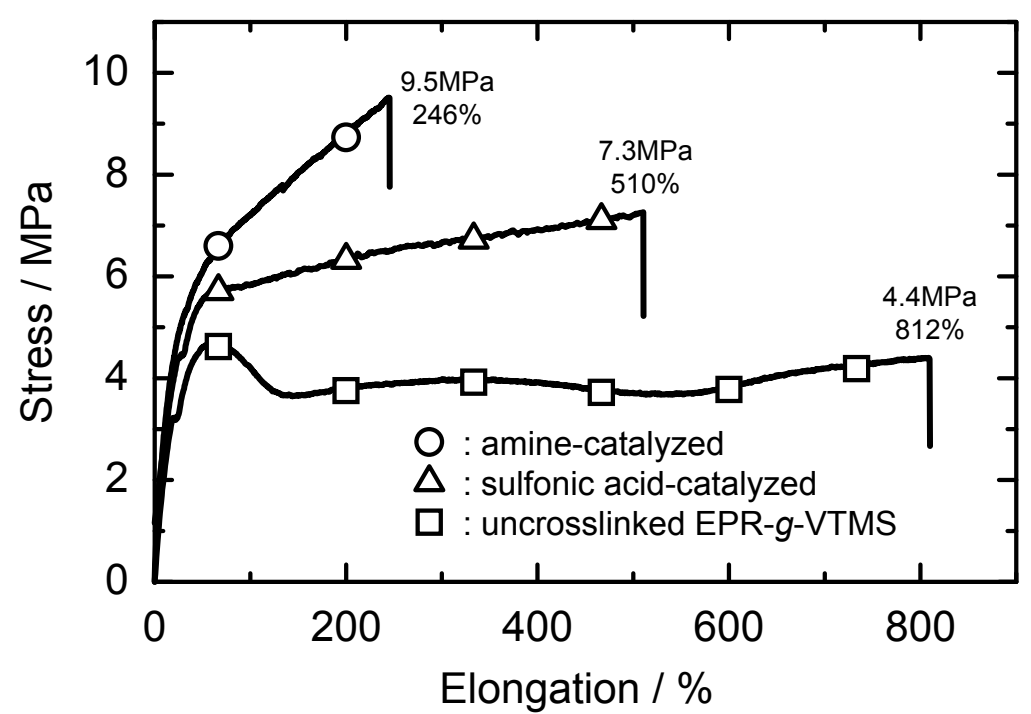




\section{Scheme 1}
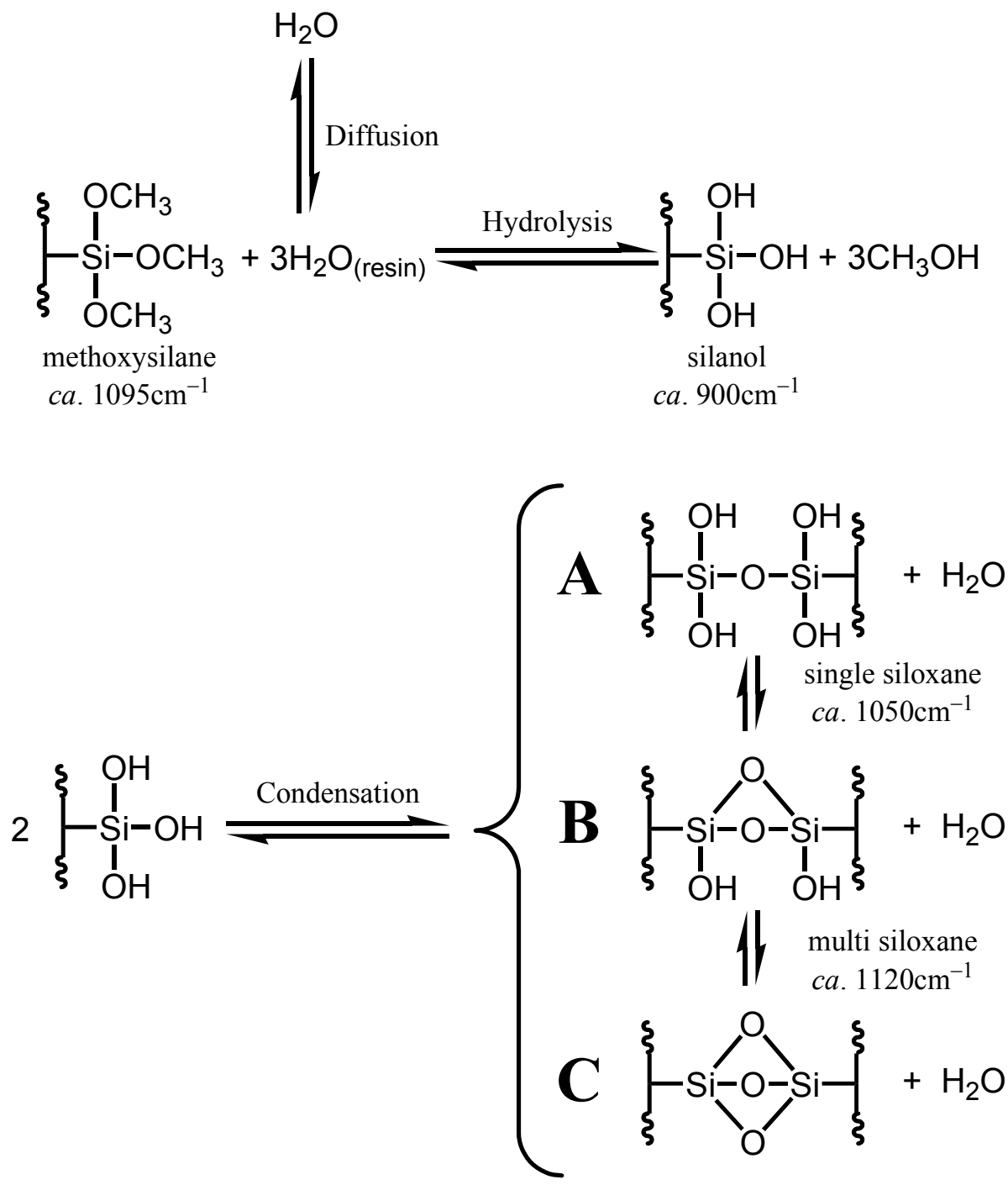
Scheme 2

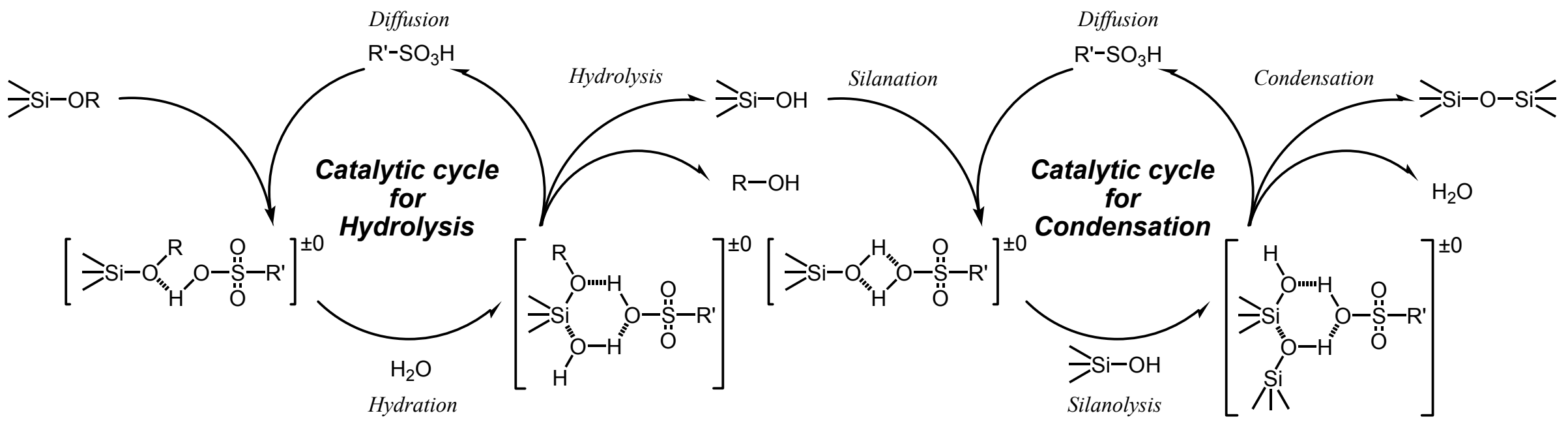


Table 1 Molar Volume $(V)$, Diffusion Constant $\left(D_{\text {sulf }}\right)$ of Sulfonic Acid into EPR at $25^{\circ} \mathrm{C}$, Frequency Factor and Activation Energy of the Hydrolysis $\left[A_{\mathrm{hyd}}, E_{\mathrm{a}, \mathrm{crk}}\right]$ and Overall Water-Crosslinking Reaction $\left[A_{\mathrm{crk}}, E_{\mathrm{a}, \mathrm{crk}}\right]$ for EPR-g-VTMS, and Calculated Average Molecular Weight between Crosslinks $\left(M_{\mathrm{c}}\right)$ for Water-Crosslinked EPR- $g$-VTMS.

\begin{tabular}{|c|c|c|c|c|c|c|c|c|}
\hline \multirow{2}{*}{\multicolumn{2}{|c|}{ catalyst $^{(a)}$}} & \multirow[b]{2}{*}{$V^{(\mathrm{b})} / \mathrm{cm}^{3}$} & \multirow[b]{2}{*}{$D_{\text {sulf }} / \mathrm{m}^{2} \mathrm{~s}^{-1(\mathrm{c})}$} & \multicolumn{2}{|c|}{ frequency factor } & \multicolumn{2}{|c|}{ activation energy $/ \mathrm{kJ} \mathrm{mol}^{-1}$} & \multirow[b]{2}{*}{$M_{\mathrm{c}} / \mathrm{g} \mathrm{mol}^{-1(\mathrm{e})}$} \\
\hline & & & & $A_{\text {hyd }}{ }^{(\mathrm{c})}$ & $A_{\text {crk }}{ }^{(\mathrm{d})}$ & $E_{\mathrm{a}, \mathrm{hyd}}{ }^{(\mathrm{c})}$ & $E_{\mathrm{a}, \mathrm{crk}}{ }^{(\mathrm{d})}$ & \\
\hline \multirow{4}{*}{$\begin{array}{l}\text { sulfonic } \\
\text { acid }\end{array}$} & $\mathrm{C} 1 \mathrm{SO}_{3} \mathrm{H}$ & 63.5 & $3.3 \times 10^{-13}$ & $(4.3 \pm 0.1) \times 10^{2}$ & $(2.8 \pm 0.9) \times 10^{8}$ & $20.4 \pm 1.9$ & $45.8 \pm 2.7$ & $(4.9 \pm 0.2) \times 10^{3}$ \\
\hline & $\mathrm{C} 3 \mathrm{SO}_{3} \mathrm{H}$ & 96.5 & $2.5 \times 10^{-13}$ & $(4.1 \pm 0.3) \times 10^{2}$ & $(2.4 \pm 0.7) \times 10^{8}$ & $20.1 \pm 2.1$ & $45.7 \pm 1.9$ & $(5.1 \pm 0.3) \times 10^{3}$ \\
\hline & $\mathrm{C}_{5} \mathrm{SO}_{3} \mathrm{H}$ & 129.6 & $3.8 \times 10^{-14}$ & $(3.7 \pm 0.1) \times 10^{2}$ & $(1.9 \pm 0.4) \times 10^{8}$ & $20.4 \pm 1.1$ & $45.0 \pm 1.3$ & $(5.0 \pm 0.2) \times 10^{3}$ \\
\hline & $\mathrm{C} 12 \mathrm{PhSO}_{3} \mathrm{H}$ & 310.0 & $6.9 \times 10^{-16}$ & $(3.4 \pm 0.1) \times 10^{2}$ & $(1.7 \pm 0.5) \times 10^{8}$ & $20.9 \pm 1.8$ & $45.3 \pm 1.7$ & $(5.0 \pm 0.2) \times 10^{3}$ \\
\hline $\begin{array}{c}\text { primary } \\
\text { amine }\end{array}$ & $\mathrm{C} 18 \mathrm{~A}^{(\mathrm{f})}$ & ------- & ------- & ------- & ------- & $16.4 \pm 3.1$ & $48.7 \pm 2.0$ & $(4.3 \pm 0.2) \times 10^{3}$ \\
\hline \multicolumn{2}{|c|}{ Without catalyst ${ }^{(\mathrm{g})}$} & ------- & ------- & ------- & ------- & $38.2 \pm 1.3$ & $84.8 \pm 3.2$ & $(5.5 \pm 0.3) \times 10^{3}$ \\
\hline
\end{tabular}

(a) catalyst concentration; $5.0 \times 10^{-4} \mathrm{~mol} / 100 \mathrm{~g}$ EPR resin, (b) calculated with ACD-Lab software (ref. [30]), (c) by means of ATR-FTIR, (d) by means of gel content, (e) aged in $80^{\circ} \mathrm{C}$ water for 24 hours, (f) C18A: $n$-octadecylamine, ref. [19], (g) ref. [23]. 